\title{
RESEARCH ON CARBON DISTRIBUTION IN NATURAL SCENIC AREA
}

\author{
Lin Chen, Rong Zhao \& Maozhu Jin* \\ School of Business, Sichuan University, Chengdu, Sichuan, China
}

Keywords: scenic area; low-carbon, carbon distribution order; Simulink simulation

\begin{abstract}
By calculating carbon sink of vegetation in a natural scenic area and tourist carbon footprint, carbon distribution load rate, carbon distribution equilibrium degree and carbon distribution order degree were introduced to study the carbon distribution order in a scenic area quantitatively. Then Simulink was used to simulate the scenic area model to get the value of carbon distribution load rate, carbon distribution equilibrium degree. On the basis of the carbon distribution situation, managerial staffs of the scenic area could modify tourists' touring routes to realize an equilibrium state of carbon distribution order and ultimately make sustainable development come true.
\end{abstract}

\section{INTRODUCTION}

The definition of "low carbon tourism" was officially put forward in a report "move forward low carbon travel and low carbon tourism" at World Economic Forum in 2009. Low carbon tourism is a tourism development model that on the premise of continuous tourism development, carbon emission can be lowered, energy consumption can be reduced during travel by "system adjustment" "technology innovation" "traditional concept transformation" to finally realize sustainable development[Xie Zhihan,2013].

In recent years, researches on low carbon tourism emerged in endlessly. [James E.S. Higham,2011], [Andrew,2010] Hares et al. studied the effect of travel by air to $\mathrm{CO}_{2}$ emission and climate change. [Becken,2004]discussed tourists' cognitive condition on the offset effect of climate change and forest carbon sink to $\mathrm{CO}_{2}$ emission. [Kuo. N, 2009]adopted LCA ( a Life Cycle Assessment) to conduct quantitative research on tourism energy use, grelen house gas emission, waste water and solid waste. [Becken,2002] tried top-down and bottom-up approaches to adjust account on tourism carbon footprint in New Zealand. [Barr S,2010] built a low carbon evaluation index system to apply various methods to the evaluation of tourism low carbon degree.

\section{BASIC CONCEPTS}

Drawing on the definition of forest carbon sink, in a natural scenic area, carbon sink means vegetation's ability to absorb and fix $\mathrm{CO} 2$ in itself.

The volume of forest carbon sink(volume of the absorbed CO2) in a time unit reflects the forest's carbon sink ability[Dong Yifei,2013]. The total carbon sink volume in a time unit is the sum of products of vegetation area multiplies per unit vegetation's absorbed CO2 volume in a time unit. Specifically, if there are $m$ kinds of vegetation in a scenic area, and the fixed carbon sink of each vegetation in a time unit is $q_{k}(1,2, \ldots, m)$, the plantation area of each vegetation is $s_{k}(1,2, \ldots, m)$, then the total carbon sink volume in a time unit is recorded as $\mathrm{C}$, and $\mathrm{C}$ is:

$$
\mathrm{C}=\sum_{k=1}^{m} s_{k}=q_{k}
$$

According to the life cycle method of carbon footprint evaluation, tourists' carbon footprint refers to the consumed carbon volume during the whole trip either produced by a traveling group or individual tourist.

In a natural scenic area, the major influential element for carbon distribution changes is tourists' carbon emission during the travel, and it includes two aspects: carbon emission from the transportation as well as from the tourists' breath.

This paper has studied the carbon footprint in transportation, and the volume of the produced $\mathrm{CO} 2$ by tourist transportation was recorded as $Q_{t}$, 


$$
Q_{t}=\sum D_{i} \cdot n_{i} \cdot \beta_{i} \cdot \alpha_{i}
$$

$Q_{t}$ refers to CO2 emission volume of transportation tool $i$; $D_{i}$ refers to the driving distance of the transportation tool $i$; $n_{i}$ refers to the number of $i ; \alpha_{i}$ is the $\mathrm{CO} 2$ emission coefficient $(\mathrm{kg} / \mathrm{MJ})$ of i's consumed energy; and $\beta_{i}(\mathrm{MJ} /$ unit.km) is the energy consumption of per unit i.

In line with the carbon footprint study of transportation, a formula to show an individual tourist's transportation carbon emission volume $Q_{t}^{\prime}$ in a time unit could be gained.

$$
Q_{t}^{\prime}=\sum_{\mathrm{i}=1}^{\mathrm{m}_{1}} \frac{W_{\mathrm{i}} \cdot V_{\mathrm{i}} \cdot \alpha_{\mathrm{i}} \cdot \beta_{\mathrm{i}}}{C_{i}}
$$

In this formula, the meaning of $\alpha_{i}$ and $\beta_{i}$ are the same with those in formula (2), $W_{\mathrm{i}}=0$ or 1 , $\sum_{\mathrm{i}=1}^{\mathrm{m}_{1}} W_{\mathrm{i}}=1 ; W_{\mathrm{i}}=0$ means tourists do not choose $\mathrm{i}$ as their transportation tools, while $W_{\mathrm{i}}=1$ means the contrary; $V_{\mathrm{i}}$ means the speed of $\mathrm{i}$; $C_{i}$ means the passengers carrying capacity of the transportation tool i.

CO2 emitted by tourist breath per day can be recorded as $0.9 \mathrm{~kg}$ per person. Carbon emission volume from tourist breath in a time unit is $Q_{b}$, and

$$
Q_{b}=\frac{0.9}{t}
$$

If $\mathrm{t}=24$, then $Q_{b}$ is the carbon emission volume from tourist breath in one hour; if $\mathrm{t}=24 \times 60$, then $Q_{b}$ is the carbon emission volume from tourist breath in one minute.

\section{MEASUREMENT OF CARBON DISTRIBUTION ORDER IN A NATURAL SCENIC AREA}

Tourist touring system of a scenic area is a carrier to provide service to the tourists. Tourist distribution in the system directly influences the carbon distribution of the scenic area. Normally, the tourist touring system is made up of scenic spots and road networks, just as Fig.1.shows.

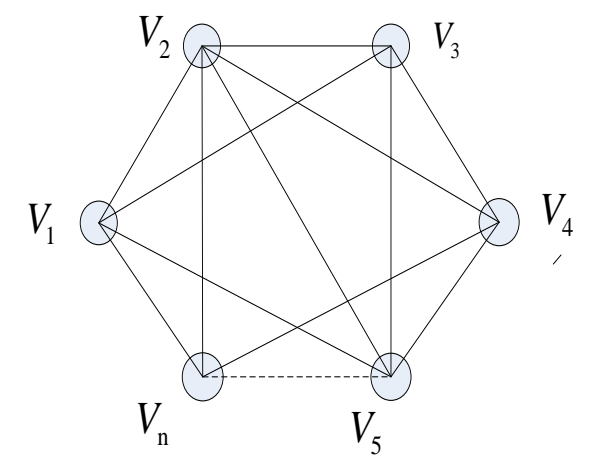

Fig.1. The tourist sightseeing system

Suppose altogether there are $\mathrm{n}$ scenic spots in a scenic area, and there are recorded as V1, $\mathrm{V} 2, \ldots \mathrm{Vn}$. The total tourist number of each scenic spot at moment $t$ is $x(t)=\left\{x_{1}(t), x_{2}(t), \ldots x_{n}(t)\right\}$. The time needed for a tourist to arrive and leave the scenic spot is $T=\left\{t_{1}, t_{2}, \ldots t_{n}\right\}$, and the time spend in each scenic spot is $\tau=\left\{\tau_{1}, \tau_{2}, \ldots \tau_{n}\right\}$. In this case, tourist carbon emission in each scenic area is: 


$$
\boldsymbol{q}_{k}=\frac{Q_{t}{ }^{\prime} \times t_{k}+Q_{b} \times\left(\tau_{k}+t_{k}\right)}{\tau_{k}}, \mathrm{k}=1,2, \ldots \mathrm{n} .
$$

As the tourist number of each scenic spot at moment $t$ is $X(t)=\left\{x_{1}(t), x_{2}(t), \ldots x_{n}(t)\right\}$, then the carbon load of scenic spot $\mathrm{i}$ at moment $\mathrm{t}$ is:

$$
l_{i}(t)=x_{i}(t) \cdot q_{i}, \quad i=1,2, \ldots n \text {. }
$$

Because the carbon sink volume of each scenic spot in a time unit is $C=\left\{c_{1}, c_{2}, \ldots c_{n}\right\}$, then the carbon load rate of scenic spot $\mathrm{i}$ at moment $\mathrm{t}$ is:

$$
r_{i}(t)=\frac{l_{i}(t)}{c_{i}}=\frac{x_{i}(t) \cdot q_{i}}{c_{i}}, \quad i=1,2, \ldots n .
$$

And the scenic area's carbon load rat

e at moment $\mathrm{t}$ is:

$$
\mathrm{R}(t)=\frac{\sum_{i=1}^{n} x_{i}(t) \cdot q_{i}}{\sum_{i=1}^{n} c_{i}} .
$$

The scenic area's equilibrium degree of carbon distribution at moment $\mathrm{t}$ is:

$$
B(t)=\sqrt{\frac{\sum_{i=1}^{n}\left(r_{i}(t)-r(t)\right)^{2}}{4} .}
$$

In formula (9), $B(t)$ represents deviation degree of the scenic area's actual carbon load rate and the most optimal load rate. The bigger the $\mathrm{B}(\mathrm{t})$ value is, the further the scenic area is from being equilibrium, and the smaller the the $\mathrm{B}(\mathrm{t})$ value is, the closer the scenic area is from being equilibrium.

\section{SIMULATION STUDY OF CARON DISTRIBUTION}

Suppose that a scenic area is a closed system, then the scenic area model can be shown as Fig.3. Altogether there are four scenic spots representing by 1,2,3, and 4 . $\mathrm{I}$ is the entrance and $\mathrm{O}$ is the exit. $\mathrm{I} \rightarrow 1, \mathrm{I} \rightarrow 2$ means from entrance to scenic spot 1 and scenic spot 2; 0.8 and 0.2 represent the two scenic spot's tourist shunting rate respectively; 20 represents the distance between I and 1, while 15 represents the distance between I and $2(\mathrm{~km})$. In the scenic area, sightseeing bus and bus are the major transportation tools. Set $q_{i}=(0.02,0.03,0.04,0.05), \mathrm{C}=(0.2,0.3,0.4,0.5)$ and $\omega=0.5$. In the model, the time unit is one minute.

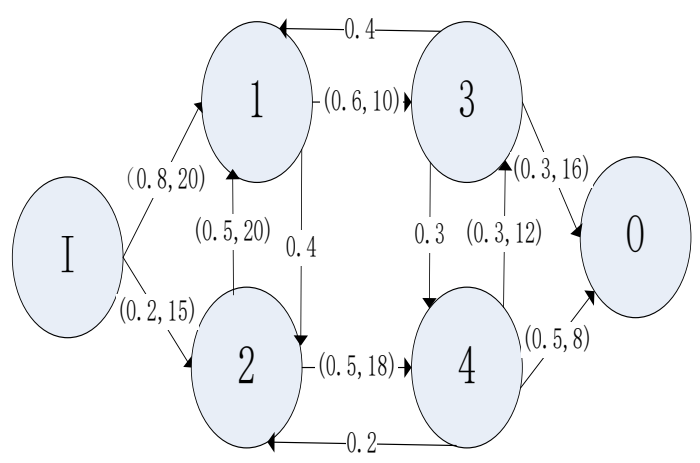

Fig.2. A Scenic Area System

The Simulink simulation model for the above scenic area model is shown as Fig.4. The simulation is done by following the above mentioned measurement process to analyze the carbon distribution order of the scenic area. 


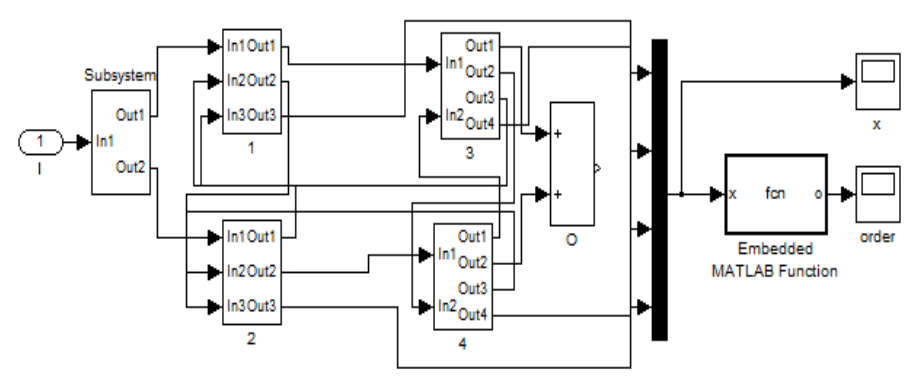

Fig. 3. The Simulation Model of the Scenic Area

Simulink uses a graphic system module to describe the dynamic system thus offering a graphical interactive environment for the users. Besides, the computing engine of MATLAB is applied to work on the dynamic system in a certain time span and a certain space[Gao Zhiyun,2012].In the model, the output of $\mathrm{X}$ represents each scenic spot's tourist number at a certain time, and the output of order represents the scenic area's carbon distribution order.

The tourist data was sourced from Jiuzhai Valley in 30th July, 2012, and it was the number of newly entered tourist in each minute for each scenic spot, recording as $x_{i}(t)$, just as Fig.5 presented. Seeing from Fig.5, in time dimension, whatever scenic spot it was, tourist number differed in different time span. And tourist number of the four scenic spots all reached their peaks during the time span of 100-200 minutes. In space dimension, tourist number differed in different scenic spots even in the same time span. Seeing from Fig.5, it could be seen that tourist number of scenic spot 1 was the biggest while in scenic spot 4, tourist number was the smallest.

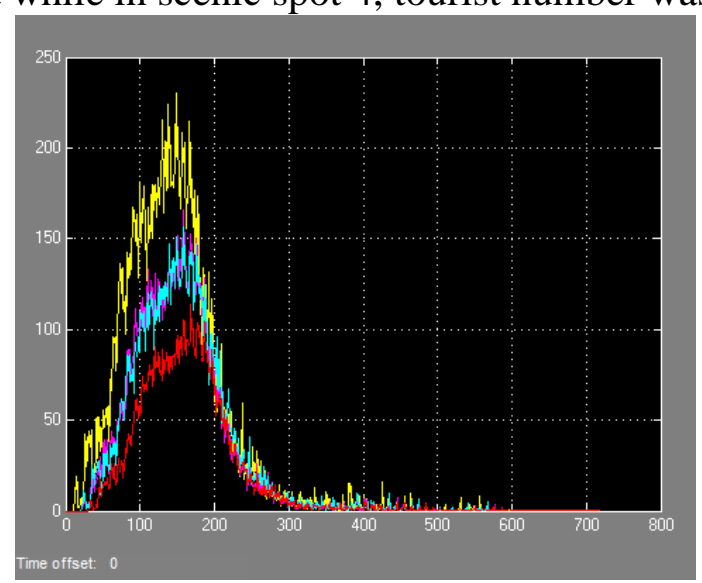

Fig. 4. Tourist number of each scenic spot

Yellow, purple, blue and red represented scenic spot 1,2,3 and 4 respectively.

The carbon distribution rate $\left(r_{i}(t)\right.$ ) of the four scenic spot in a day was shown in Fig.5. It could be observed that the carbon distribution load rate was in strong conformity with tourist distribution of the scenic spot, illustrating that carbon distribution load rate could well reflect the scenic area's tourist distribution. 


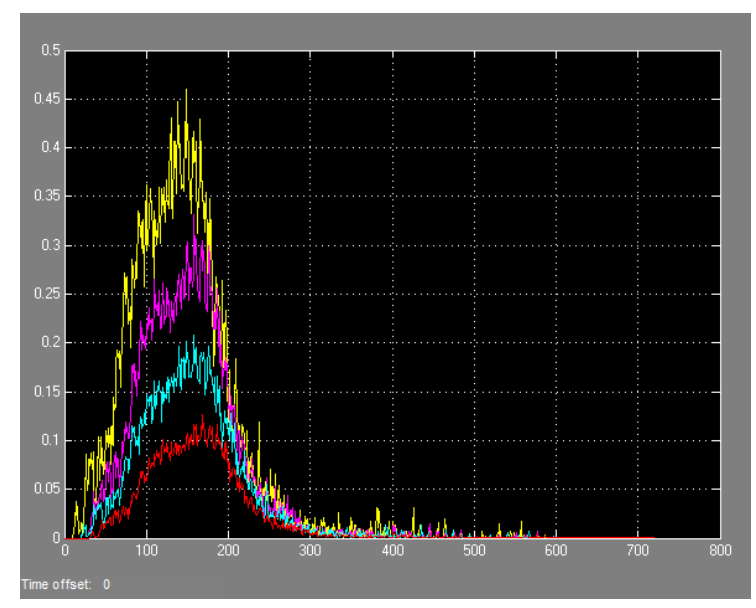

Fig. 5. Carbon distribution load rate of each scenic spot

The scenic area's carbon distribution load rate $\mathrm{R}(\mathrm{t})$ was shown in Fig.6. Seeing from the Fig, it could be told that during the time span of 80-200 minutes, the scenic area's carbon distribution load rate was beyond 1 , and it was less than 1 in other time span. Therefore, it was necessary to guide tourists to different scenic spot at different time of a day.

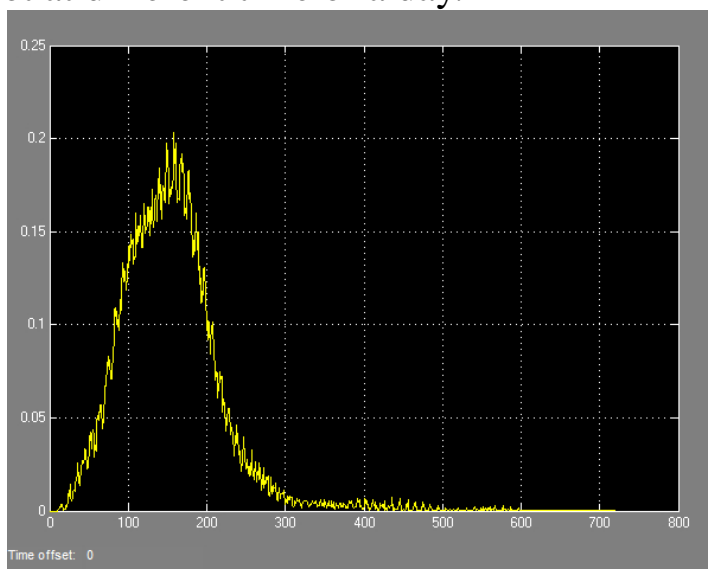

Fig. 6. Carbon distribution load rate of the scenic area

The scenic area's carbon distribution equilibrium degree $\mathrm{B}(\mathrm{t})$ was shown in Fig.7. Judging from Fig.8, it could be told that during the time span of 80-200 minutes, the equilibrium degree $\mathrm{B}(\mathrm{t})$ was relatively high, indicating that in other time spans, the equilibrium degree was not that good. Therefore, it was necessary to adjust tourist distribution by guiding tourists move from high load rate scenic spot to those with lower load rate.

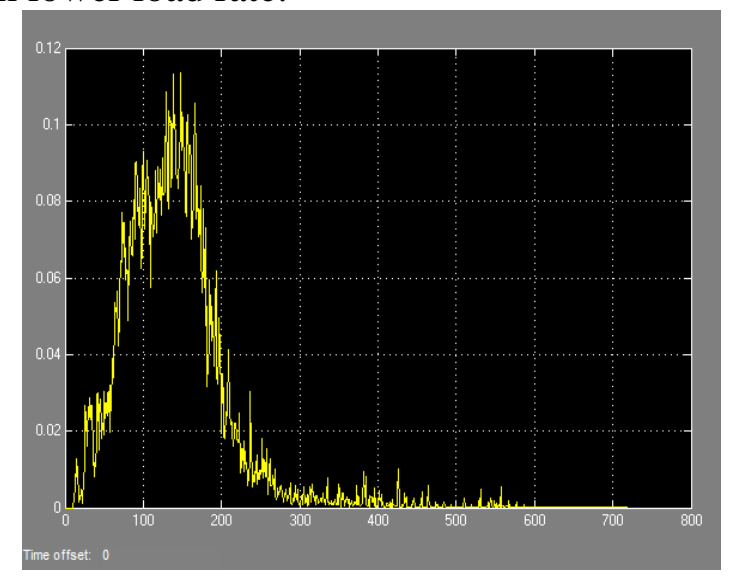

Fig.7. Carbon distribution equilibrium degree of the scenic area 
Judging from Fig.8, carbon distribution order degree was obviously higher during the time span of 100-200 minutes, as a result, managerial staffs should take correspondent adjustment measures to balance the scenic area's carbon distribution order. On one hand, senior managerial staff should control the ceiling of tourist numbers and launch decisions to guide tourists entering the scenic area at a different time. On the other hand, the primary level managerial staffs should adopt appropriate measures to adjust touring routes, guiding tourists move from high load rate scenic spot to those with lower load rate. With macro and micro measures, the carbon distribution order would become balanced and so would tourist distribution in time and space dimension. Finally, the scenic area's ecological environment could be protected and sustainable development could be realized.

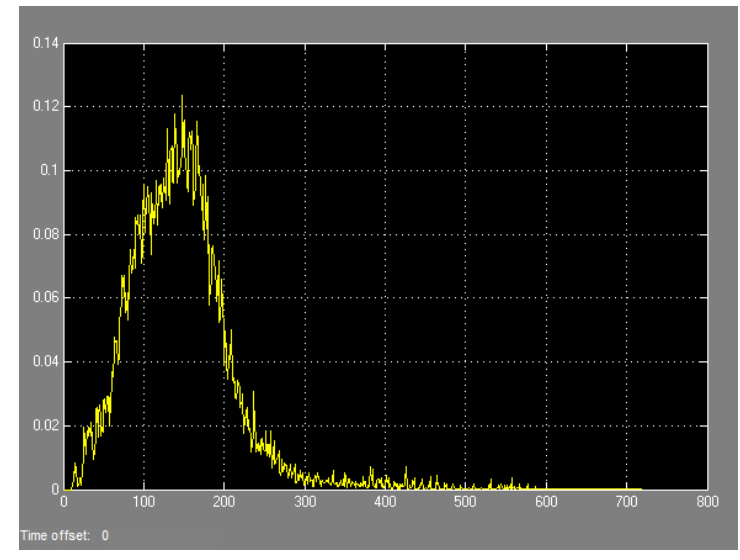

Fig.8. Carbon distribution order degree of the scenic area

\section{CONCLUSION}

This paper, by calculating tourist carbon footprint and the scenic area's carbon sink ability, successfully got the carbon distribution load rate and carbon distribution equilibrium degree of the scenic area, making the measurement of carbon distribution order of the scenic area a possible thing. In the end, Simulink was used to do a simulation study of the natural scenic area's carbon distribution. Thanks to this simulation, the managerial staffs could get direct data, have a better understanding of the scenic area's carbon distribution situation and make timely measures to adjust tourist distribution. In this case, no scenic spot would suffer from a long-term overload burden which would definitely damage partial ecological environment, and eventually the ecological environment of the whole scenic spot could be protected.

\section{REFERENCES}

[1] Xie Zhihan, Han Junqing. Study of Low-carbon Tourism and its Development Strategies in Linfen, Shanxi Province. Journal of Green Science and Technology[J], 2013(2):262-264.

[2] James E.S. Higham, Scott A. Cohen. Canary in the coalmine: Norwegian attitudes towards climate change and extreme long-haul air travel to Aotearoa/New Zealand[J].Tourism Management, 2011(32):98-105.

[3] Andrew Hares, Janet Dickinson, Keith Wilkes. Climate change and the air travel decisions of UK tourists[J].Journal of Transport Geography,2010(18):466-473.

[4] BECKENS. How tourists and tourism experts perceive climate change and carbon offsetting schemes[J] . Sustainable Tourism,2004, 12( 4) : 332- 345. 
[5] Nae-Wen Kuo, Pei-Hun Chen. Quantifying energy use, carbon dioxide emission, and other environmental loads from island tourism based on a life cycle assessment approach[J]. Journal of Cleaner Production, 2009, (17): 1324-1330.

[6] Becken S, Simmons D G. Understanding energy consumption patterns of tourist attractions and activities in New Zealand[J]. Tourism Management, 2002, 23(4): 343-354.

[7] Barr S, Shaw G, Coles T, et al. 'A holiday is a holiday': practicing sustainability, home and away[J]. Journal of Transport Geography, 2010, 18(3): 474-481.

[8] Dong Yifei. Measure and analyze the carbon source and carbon skin of Mountain tourism[D]. Southeast University, 2013.

[9] Gao Zhiyun, Liu Bo, Liu Hongbo. Study on Simulink Simulation Technology for Urban Pipeline Water Distribution System Based on Fuzzy Theory[J]. Journal of Anhui Agricultural Sciences, 2012,05:2984-2987+2990. 